\title{
Transposase is the only nematode protein required for in vitro transposition of Tc1
}

\author{
Jan C. Vos, Ivo De Baere, and Ronald H.A. Plasterk ${ }^{1}$ \\ The Netherlands Cancer Institute, Division of Molecular Biology, 1066 CX Amsterdam, Netherlands
}

\begin{abstract}
The Tc1 element of Caenorhabditis elegans is a member of the most widespread class of DNA transposons known in nature. Here, we describe efficient and precise transposition of Tc1 in a cell-free system. Tc1 appears to jump by a cut-and-paste mechanism of transposition. The terminal 26 bp of the Tc1 terminal repeats together with the flanking TA sequence are sufficient for transposition. The target site choice in vitro is similar to that in vivo. Transposition is achieved with an extract prepared from nuclei of transgenic nematodes that overexpress Tc1 transposase but also by recombinant transposase purified from Escherichia coli. The simple reaction requirements explain why horizontal spread of Tc1/mariner transposons can occur. They also suggest that Te1 may be a good vector for transgenesis of diverse animal species.
\end{abstract}

[Key Words: C. elegans; in vitro transposition; Tc1; transgenesis]

Received December 18, 1995; revised version accepted January 29, 1996.

Tc1 belongs to the Tc1/mariner superfamily of transposons found in nematodes, arthropods, and chordates (Henikoff 1992; Radice et al. 1994; Plasterk 1995; Robertson 1995). Both vertical and horizontal transfer have contributed to the spread of these elements throughout the animal kingdom (Robertson 1993; Radice et al. 1994; Robertson and Lampe 1995). The widespread occurrence of the Tc1/mariner family of transposons can be taken as an indication of the absence of species-specific host factors that limit the transfer between different species. Therefore, Tc1/mariner elements might be attractive candidates for the development of gene delivery vectors.

Tc1-like elements are close to $1.7 \mathrm{~kb}$ in length, have short inverted terminal repeats flanking a transposase gene, and have the conserved sequence CAGT at their termini, flanked by TA representing the target site, which is duplicated upon integration (Van Luenen et al. 1994). The element-encoded proteins share a homologous catalytic domain with bacterial transposases and retroviral integrases (Doak et al. 1994). Tc1 from C. elegans is a 1612-bp-long transposon that has 54-bp inverted repeats flanking a gene encoding a 343-amino-acid transposase (Emmons et al. 1983; Rosenzweig et al. 1983; Vos et al. 1993), which binds to the inverted repeats (Vos et al. 1993; Vos and Plasterk 1994). The conserved hexanucleotide sequence, TACAGT, at the extreme termini of the element is not part of the transposase binding site but is thought to play a role in catalysis of the transposition reaction (Vos and Plasterk 1994).

Here, we describe in vitro excision and transposition of Tc1 using an extract prepared from transgenic nematodes. The minimal cis-acting requirements for transpo-

\footnotetext{
${ }^{1}$ Corresponding author.
}

sition are defined, and the target site choice in vitro is compared with that in vivo. Furthermore, we demonstrate that recombinant transposase purified from $E$. coli is capable of supporting transposition, showing that no other factors are essential for Tc1 transposition in vitro.

\section{Results}

\section{Transposition of Tc1 in vitro}

We generated a transgenic worm with the Tc1 transposase gene under the control of a heat shock promoter. This allowed the preparation of a nuclear extract with elevated levels of transposase, which proved to be essential to detect activity. The extract was incubated with a plasmid containing a Tc1 element. Excision was studied in a physical assay. Southern blot analysis of reaction products shows the appearance of excised Tc1 elements (Fig. 1, lane 1). Furthermore, cleavage at either the left or the right end of Tc1 is detected when the products are digested with $S c a$ I within the plasmid backbone prior to electrophoresis (lane 2). Cleavage requires a divalent cation $\left(\mathrm{Mg}^{2+}\right.$ or $\left.\mathrm{Mn}^{2+}\right)$ and is stimulated by the presence of $10 \%$ ethylene glycol or $5 \%$ DMSO (data not shown). The efficiency of cleavage at a single end of the transposon is not decreased if the substrate is linear (cf. lanes 2 and 5). Also, deletion of either end of the transposon does not abolish cleavage at the remaining end (lanes 6-11), which suggests that cleavage does not require interaction between the two ends. In contrast to single end cleavage, excision of the complete element is reduced about twofold when the substrate is linear, suggesting that coordinated cutting at both ends is stimulated by supercoiling of the substrate. The majority of complete excision products observed with a linear substrate can be explained by noncoordinated cleavages at both ends. 


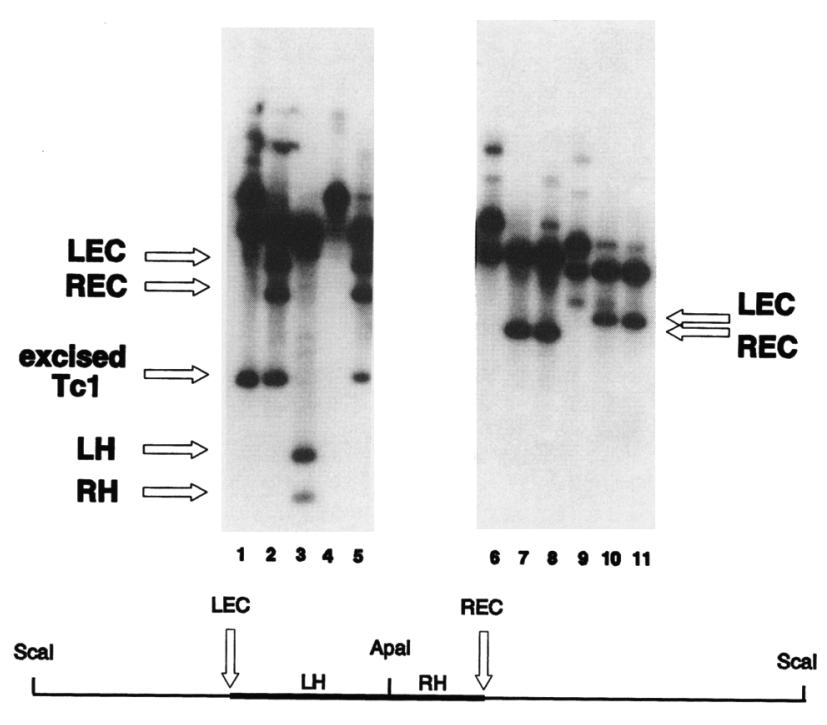

$0.5 \mathrm{~kb}$

Figure 1. Southern blot analysis of in vitro Tc1 transposition reaction products. Products of in vitro transposition reactions were separated on a $1 \%$ agarose gel, transferred to nitrocellulose, and probed with radiolabeled Tc1. Standard reactions contained $\mathrm{MgCl}_{2}$ (lanes 1-3,5-11) or EDTA (lane 4). Products were digested with $S c a I$ in vector DNA $\{$ lane $2,7,10\}$ or Apal in Tc1 DNA (lane 3) prior to electrophoresis. Lanes $5,8,11$ show reaction products when the substrate is linearized with $S c a$ I prior to in vitro cleavage. Lanes $1-5$ show reaction products using pRP466 as substrate that carries a complete Tc1 element. Lanes 6-8 use pRP467 as substrate that has a deleted left end of Tc1, whereas lanes 9-11 show pRP468 as substrate, which has the right end of Tc1 deleted. REC and LEC stands for right and left end cleavage, respectively. $\mathrm{RH}$ and $\mathrm{LH}$ indicate the positions of the right and left half of Tc1. A schematic of Scal-linearized pRP466 is shown at the bottom.

To determine the positions of the double-strand cleavages at the nucleotide level, a PCR-based primer extension was performed using end-labeled oligonucleotides specific for each strand (Fig. 2). The $5^{\prime}$ cut is 2 bp within the transposon, whereas the $3^{\prime}$ cut maps to the end of the transposon, as based on the largest observed PCR product. This confirms the model based on in vivo studies of the related C. elegans transposon Tc3, for which it was shown that excision results in a 2-bp staggered $3^{\prime}$ overhang (Van Luenen et al. 1994). The complete excision of Tc1 suggests that transposition occurs via a cut-andpaste process, a result consistent with genetic data on double-strand break repair of the donor DNA molecule upon Tc1 excision (Plasterk 1991).

We devised a sensitive assay to detect integration events. We selected for jumping of a transposon-borne antibiotic resistance gene from a supercoiled donor plasmid to a target plasmid in a genetic assay (Fig. 3). Electroporation of reaction products into the appropriate $E$. coli strain resulted in the detection of many transposition events (Table 1). Extracts prepared from nontransgenic N2 worms or from the so-called high-hopper
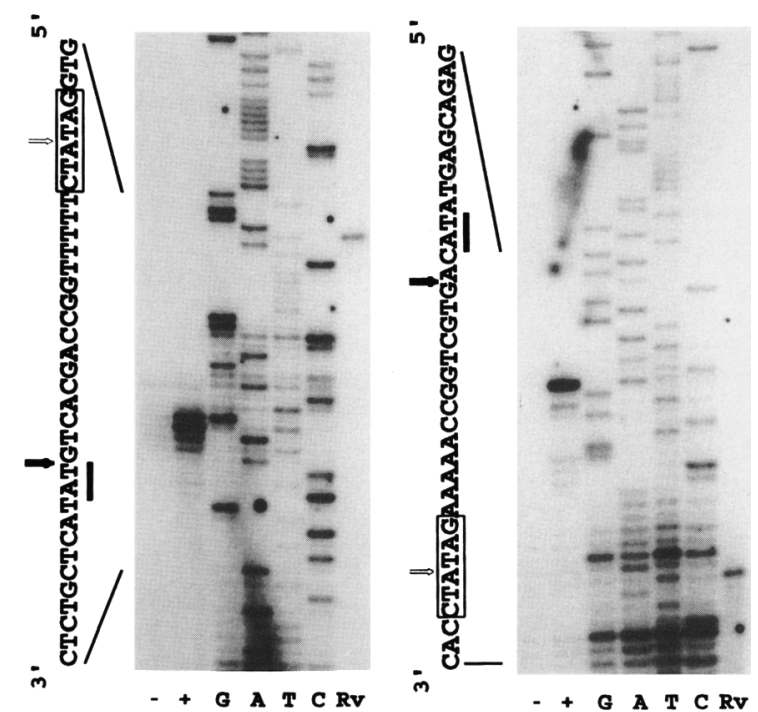

Figure 2. Mapping of the in vitro cleavage sites at the nucleotide level. A PCR-based primer extension was performed on reaction products obtained in the presence of $\mathrm{MgCl}_{2}(+)$ or EDTA (-) using pRP466 as donor. A control reaction was performed with pRP466 digested with EcoRV (RV lanes) to demonstrate the addition of one extra nucleotide at the end of the PCR product by Taq polymerase (see Clark 1988). Products were analyzed on a sequencing gel. Sequence reactions (GATC) were loaded as markers. PCR was with primer R2 (right) or primer BIGR (left). The relevant sequence is indicated with the EcoRV site boxed and the TA target site underlined. The cleavage sites are shown by arrows. Identical results were obtained when the positions of cleavage at the other transposon end were determined.
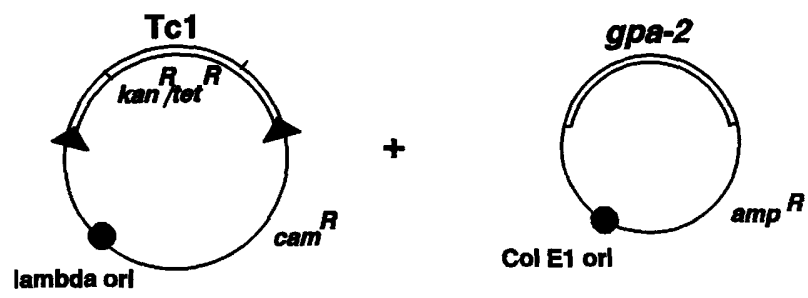

Col E1 orl

In vitro transposittion

electroporate Into DS941 lambda lysogen

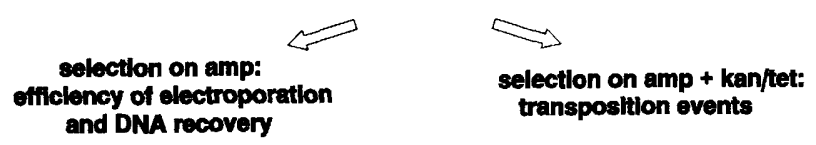

Figure 3. Schematic representation of the genetic transposition assay. The donor plasmid, a pACB104 derivative (Boyd and Sherratt 1995) with a lambda origin of replication, contains a $\mathrm{Tc} 1$ element carrying an antibiotic resistance gene. The target plasmid, pRP475, carries a 1.4-kb HindII gpa-2 fragment and a Col El origin of replication (pSP72, Promega). Reaction products were electroporated into a lambda lysogen $E$. coli strain to counterselect against the donor. Integration events were selected on double antibiotics. 
Table 1. Transposition frequencies

\begin{tabular}{llcc}
\hline Donor & Source & Exp. 1 & Exp. 2 \\
\hline pRP490, SC & C. elegans & 21 & 22 \\
pRP490, linear & C. elegans & 0.5 & 1.0 \\
pRP491, SC & C. elegans & 3.7 & 1.6 \\
pRP490, SC & E. coli & 3.0 & 3.2 \\
\hline
\end{tabular}

In vitro Tc1 transposition reactions were carried out with supercoiled (SC) or linear donor plasmids and with protein sources as indicated, and the ratios of $A m p^{R}-K_{a n}{ }^{R}$ to $A m p^{R}$ colonies $\left({ }^{\star} 10^{6}\right)$ are shown for two independent experiments. No integration products were recovered when reactions were performed in the presence of EDTA.

strain, TR679 (Collins et al. 1987), which has a high frequency of germ-line transposition, do not generate a detectable level of transposition products in this assay. Linearization of the donor plasmid resulted in an $\sim 20$-foldreduced efficiency of transposition. Transposition requires two inverted repeat sequences, because no integrations were obtained upon deletion of one transposon end. Furthermore, the addition of ATP, GTP, or dNTPs does not increase the level of transposition /data not shown/, which suggests that the process is neutral in energy consumption and independent of a cofactor. About 90 independent in vitro Tc1 integrations were analyzed by sequencing and found at TA dinucleotides, which had been duplicated in the process. Two odd integration events were detected, where Tc1 had inte- grated in the sequence TTG or CCT. In both cases we found a 3-bp target site duplication.

\section{Target site choice}

Previously, several hundred in vivo Tc1 and Tc3 integrations in a $1-\mathrm{kb}$ region of the gpa-2 gene have been analyzed (Van Luenen and Plasterk 1994). This showed the selective use of a limited set of TA dinucleotides as targets of integration, with a striking difference in preference between Tc1 and Tc3. To investigate whether the chromatin structure played a role in the choice of integration sites, we determined the pattern of integrations into naked DNA in vitro, using the same target region assayed previously in vivo. Therefore, we included the gpa-2 region in our target plasmid. It is apparent that the same overall pattern of integration is seen (Fig. 4). Hot sites in vivo appear to be hot in vitro and cold sites in vitro are also cold in vivo. This indicates that, at least in this region of the genome, the chromatin structure or the transcriptional status of the DNA in vivo is not the major determinant of target choice.

\section{Transposition by recombinant transposase}

The nematode is not a convenient source of protein for an extensive purification of transposase. Therefore, we expressed the protein in a heterologous system. Both expression using baculovirus and Sf9 cells (data not shown) or expression in E. coli yielded transposase capable of

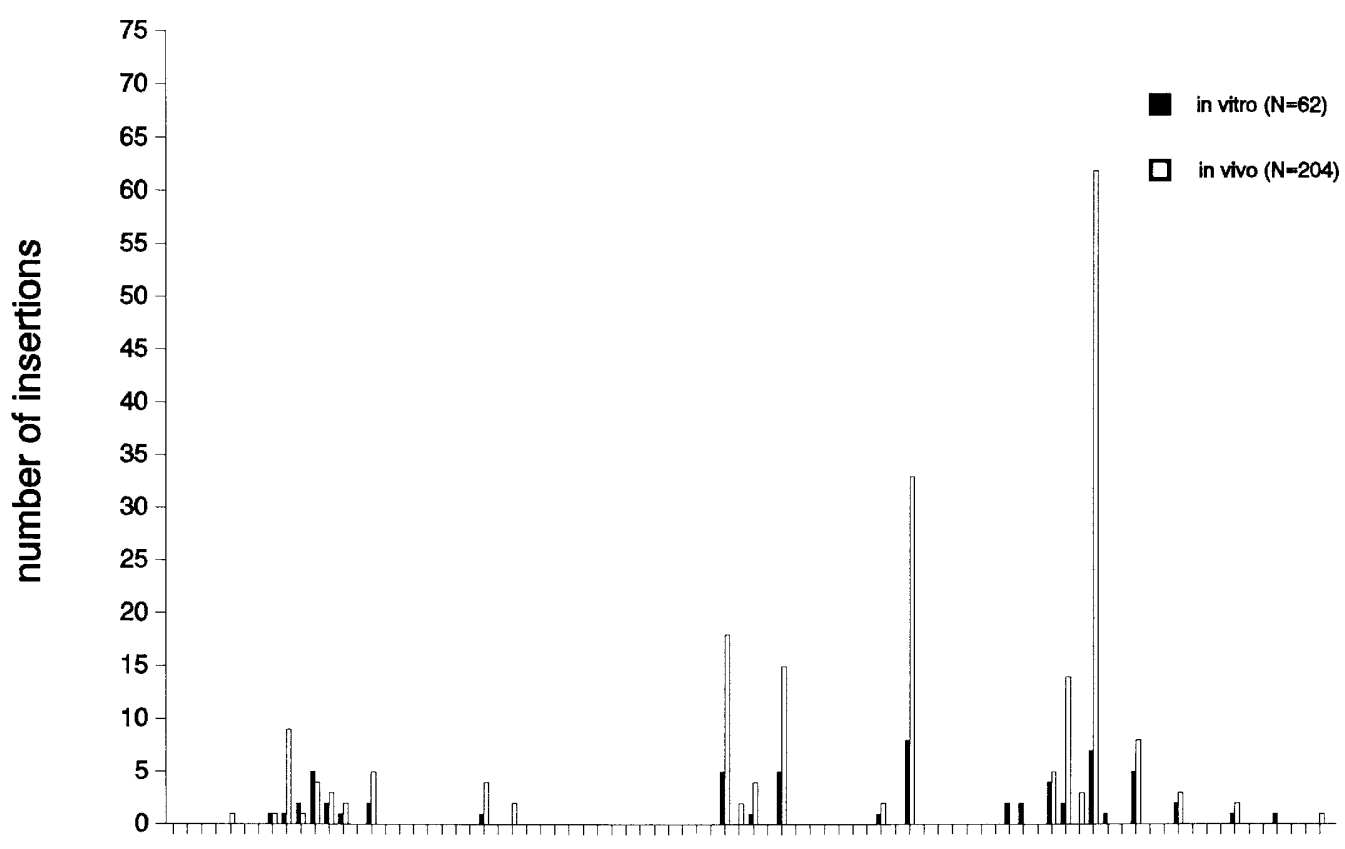

TA dinucleotides

Figure 4. Target site selection. Comparison of the distribution of in vitro (solid bars) and in vivo (open bars) Tc1 insertions. pRP472 as donor and pRP475 as target were used in standard in vitro transposition reactions using C. elegans extract. Every mark on the $x$-axis represents a TA dinucleotide in the gpa-2 gene fragment as described in detail elsewhere (Van Luenen and Plasterk 1994). 
Vos et al.

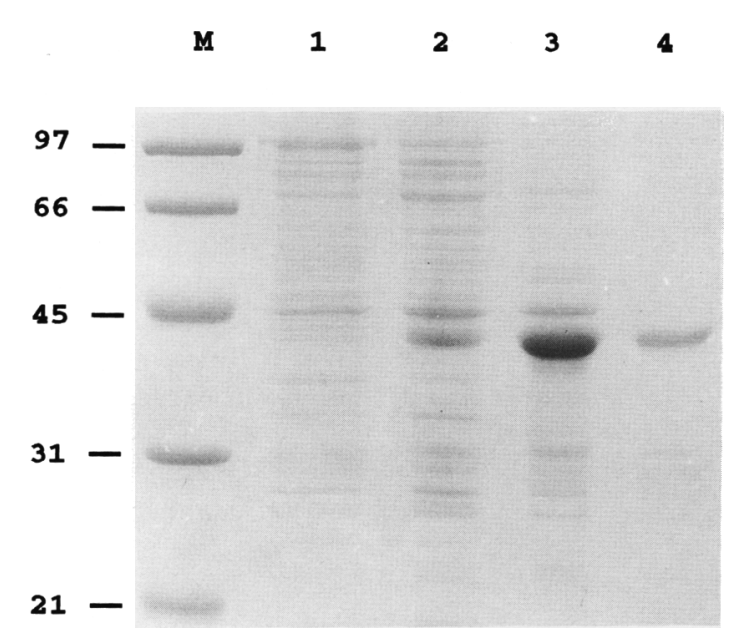

Figure 5. Purification of Tc1 transposase from E. coli. Analysis of transposase purified from inclusion bodies on a $12 \%$ SDSpolyacrylamide gel. (Lane $M$ ) Molecular mass markers (indicated in $\mathrm{kD}$ ); (lane 1) bacterial lysate before induction; (lane 2) bacterial lysate after induction; (lane 3) purified inclusion bodies; (lane 4) purified transposase after refolding.

supporting Tc1 transposition. Recombinant transposase was purified from inclusion bodies to near homogeneity (Fig. 5). Table 1 shows the frequency of transposition when comparable amounts of transposase were used for both the worm extract and the purified protein. Sequence analysis of nine independent integrations in case of the recombinant protein showed that transposition occurred in TA target sequences that were duplicated, from which it can be concluded that bona fide transposition had occurred. Therefore, we conclude that Tc1 transposase is the only protein required for Tc1 transposition. The difference in efficiency between nematodederived and bacterial transposase needs further studies. It could reflect a folding problem of the bacterial transposase, which was denatured and refolded during the purification procedure, or the stimulatory role of host factors present in the nematode extract.

\section{Minimal cis-requirements}

We investigated the possibility that the terminal $26 \mathrm{bp}$ of Tc1 that constitute a full transposase binding site, flanked by the TA target site, are sufficient to form an artificial transposon. An element consisting of only these Tc1-specific sequences is still able to transpose in vitro, albeit at a lower frequency (Table 1). We sequenced several integrations and found them to be correct.

Furthermore, we investigated the importance of the conserved hexanucleotide sequence TACAGT. Mutations were introduced at one of the ends of a mini-Tc1 that contains only the terminal $26 \mathrm{bp}$ as well as the flanking TA dinucleotide. Whereas excision of the element with two wild-type ends is easily detected in a physical assay, mutation of the transposase binding site, the flanking TA sequence, or the CA or GT sequence of the termini resulted in the inability of the element to excise (Fig. 6). Double-strand cleavage at the wild-type end was not affected by mutation at the other transposon end. Analysis of cleavage by PCR-based primer extension revealed that, for the CA to TG mutation only, singlestranded breaks at the $5^{\prime}$ end of the transposon had occurred (data not shown).

\section{Discussion}

We have developed a cell-free Tc1 transposition system. Excision occurs by double-strand breaks at the transposon ends resulting in 2-bp staggered 3 ' overhangs. A cutand-paste mechanism of transposition appears to apply for Tc1 (Fig. 7). This mechanism was already proposed on the basis of genetic data (Plasterk 1991) as well as the analysis of in vivo transposition products (Van Luenen et al. 1994). Nonreplicative transposition is shared with the

\section{flank-TACAGT--TBS--Tc1}

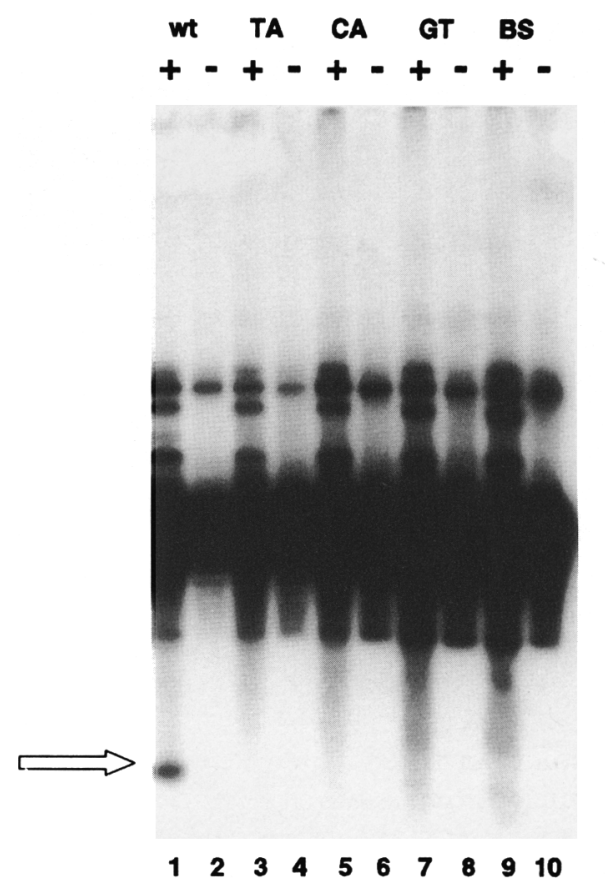

Figure 6. Mutations at the extreme termini of Tc1 affect excision. In vitro reaction products were obtained using C. elegans extract in the presence of $\mathrm{MgCl}_{2}(+)$ or EDTA (-) using as donor pRP480 (wt), pRP481 (TA), pRP482 (CA), pRP483 (GT), or pRP484 (BS), as indicated at the top. Products were separated on a $1 \%$ agarose gel, transferred to nitrocellulose, and probed with radiolabeled $\mathrm{Kan}^{\mathrm{R}}$-gene fragment. The donor plasmids contain 28-mer cloned into the SmaI-site (wt sequence) and the HindIIsite (wt or mutant sequence) of pUC19 with the $\mathrm{Kan}^{\mathrm{R}}$-cassette of pUC4K in between. TA was mutated to CG, CA to TG, and GT to AC, respectively. In the transposase binding site mutation, the Ball and EcoRV sites are mutated to TCCCCA and GGGCCC, respectively (see Vos and Plasterk 1994). 


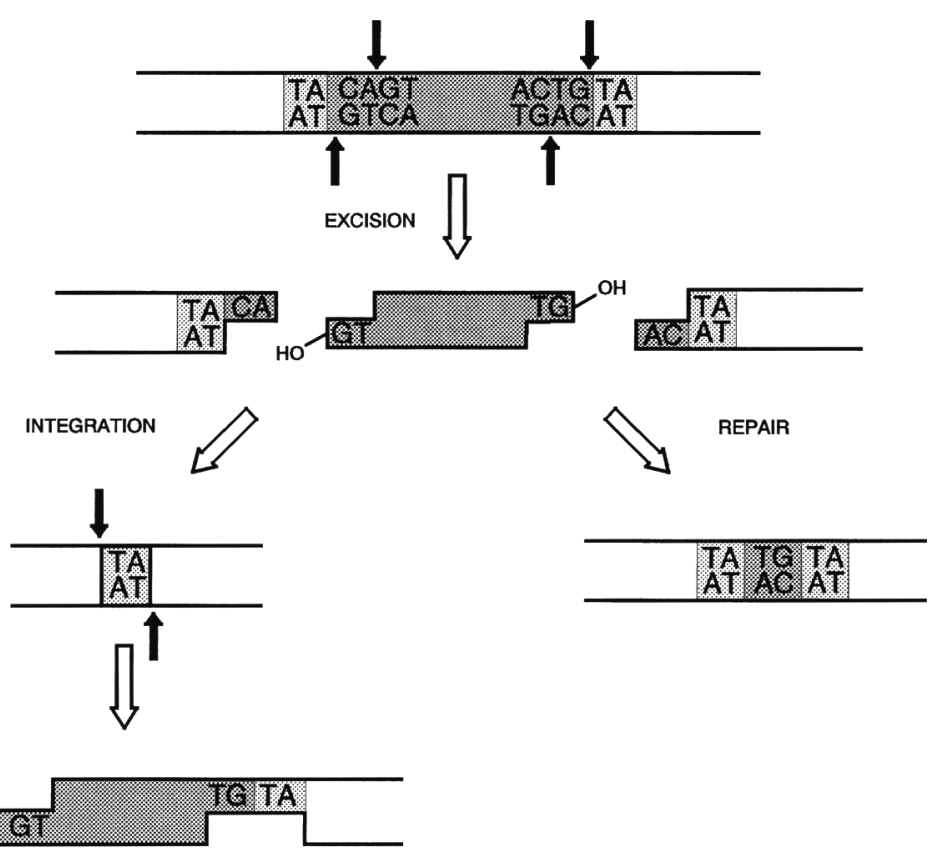

Figure 7. Model for Tc1 transposition. A model for nonreplicative Tc1 transposition showing the excised, linear element with a 2-bp $3^{\prime}$ staggered overhang. Integration results in a duplication of the TA target site. Repair of the double-strand break leads to the generation of characteristic footprints (see also Van Luenen et al. 1994). bacterial transposons Tn7 (Bainton et al. 1991, 1993) and Tn10 (Bender and Kleckner 1986) as well as the Drosophila P element (Kaufman and Rio 1992). In contrast, the $\mathrm{Mu}$ and Tn3 transposable elements transpose via a replicative mechanism /Grindley and Sherratt 1978; Shapiro 1979; Mizuuchi 1992). Tc1 transposition appears to be independent of addition of a nucleotide cofactor, whereas P elements use GTP (Kaufman and Rio 1992) and Tn7 uses ATP as cofactor (Bainton et al. 1993).

A striking feature of the Tc1/mariner family is the absolute use of a TA dinucleotide as target site. An extensive study of target site choice in vivo had revealed the usage of only a subset of the available TA dinucleotides and a marked difference in target choice between the two related transposons $\mathrm{Tc} 1$ and $\mathrm{Tc} 3$ in C. elegans (Van Luenen and Plasterk 1994). We find the same overall integration pattern in vitro as had been observed in vivo. This suggests that the chromosomal context of the DNA does not affect target choice, at least in the region of the genome analyzed. Therefore, we favor the idea that the transposition complex primarily selects its target site on the basis of the primary DNA sequence flanking the TA, although a strong consensus sequence could not be identified (Van Luenen and Plasterk 1994). A clear influence of the chromatin structure has been demonstrated for retroviral integrations (Pryciak and Varmus 1992; Müller and Varmus 1994). These studies showed a preference for regions within nucleosomal DNA, probably owing to the bending of the DNA. We cannot exclude that DNA-binding proteins can affect regional preferences for Tc1 integration. Because nothing is known about the chromosomal organization of the gpa-2 gene, it will be of interest to compare integration sites using reconstituted nucleosomal DNA in vitro.

Transposition in vitro requires the extreme termini of the transposon containing the transposase binding site and the conserved hexanucleotide sequence, which is important for excision. We observe a decrease in transposition efficiency between transposition of a full-length transposon and the Tc1 element with only 26-bp terminal inverted repeats, which suggests that additional sequences can contribute to transposition efficiency. We have no indications for additional transposase binding sites, but perhaps small basic proteins like high-mobility group proteins (Grosschedl et al. 1994) may bind and stimulate transposition. Alternatively, unique A-T-rich sequences found at the transposon ends may add a helping bend to the DNA. The conserved hexanucleotide sequence at the extreme termini of the transposon is shown to be important at least for the cleavage step. The 5 '-end single-strand cleavage seen for one of the mutations (CA to TG) is perhaps an indication for a specific order of single-strand cleavages, that is, the nontransferred strand first, which would be the opposite of what has been reported for Tn10 (Bolland and Kleckner 1995).

Transposase purified from $E$. coli to near homogeneity is able to execute jumping of $\mathrm{Tc} 1$, which indicates that transposase is the only protein required for excision and integration of Tc1. The higher efficiency obtained with the nematode extract suggests that host factors may enhance the frequency of the reaction. It has, for instance, been shown that the mammalian proteins HMG1 and HMG2 can stimulate prokaryotic recombinations (Paull et al. 1993). The independence of species-specific factors might be the explanation why members of the Tc1/mariner family are dispersed over so many different phyla, possibly by means of horizontal transfer (Robertson and Lampe 1995). This is in contrast to P elements that are restricted to Drosophila species. Transposition of P elements in other species has not been observed (Rio et al. 
1988). A possible candidate for a species-specific host factor in $\mathrm{P}$ transposition is the inverted repeat-binding protein, IRBP (Beall et al. 1994). The simple cis- and trans-requirements for $\mathrm{Tc} 1$ transposition in vitro suggest that this transposable element may be a good vector for gene delivery in a wide variety of animals.

\section{Materials and methods}

\section{Plasmid constructions}

pRP466 contains a Tc1 element with 0.4-kb flanking sequences derived from pIM40 (Mori 1988) cloned as a BamHI-XbaI fragment into pUC19. pRP467 and pRP468 are derivatives of pRP466 in which either a ClaI-Asp718 or a PstI-ApaI fragment is deleted. pRP472 is a pACB104 (Boyd and Sherratt 1995) derivative that contains $\mathrm{Tc} 1$ with the AvaI-HindIII fragment of pBR322 inserted between the ClaI and ApaI sites. Cloning of the XbaI-BamHI fragment of pRP466 with the HindII Kan ${ }^{\mathrm{R}}$-cassette of pUC4K (Pharmacia) between the XhoI sites into pACB104 resulted in pRP490. pRP491 is comparable to pRP490; all the internal Tc1 sequences have been replaced except the terminal $26 \mathrm{bp}$.

\section{Transgenesis of $\mathrm{C}$. elegans}

A transgenic Bristol line was obtained after microinjection (Mello et al. 1991) of $150 \mu \mathrm{g} / \mathrm{ml}$ of pRP469 and $5 \mu \mathrm{g} / \mathrm{ml}$ of pRP465 (Vos et al. 1993), $50 \mu \mathrm{g} / \mathrm{ml}$ of pRF4 (Kramer et al. 1990) in strain CB1392[nuc-1(e1392)]. A stable line, NL818(pkIs221), was generated by X-ray irradiation (Way et al. 1991).

\section{Extract preparation}

Stable line NL818 was grown in liquid culture at $18^{\circ} \mathrm{C}$ and heat shocked for $3 \mathrm{hr}$ at $33^{\circ} \mathrm{C}$ to induce transposase expression. After $2 \mathrm{hr}$ of further growth at $18^{\circ} \mathrm{C}$, nuclear extracts were prepared as described (Vos et al. 1993) with differences in the buffers. NIB: $25 \mathrm{~mm}$ Tris (pH 7.5), $20 \mathrm{~mm} \mathrm{KCl,} 0.5 \mathrm{M}$ sucrose, $0.5 \mathrm{~mm}$ EDTA, $5 \mathrm{mM} \beta$-mercaptoethanol, $0.1 \mathrm{mM}$ PMSF. NEB: $25 \mathrm{mM}$ Tris $(\mathrm{pH}$ 7.5), $0.1 \mathrm{~mm}$ EDTA, $500 \mathrm{~mm} \mathrm{NaCl}, 15 \%$ glycerol, $0.25 \%$ Tween 20, 0.1 mM PMSF, $1 \mathrm{~mm}$ DTT. Nuclear extract contains 2.5 $\mathrm{mg} / \mathrm{ml}$ of protein; concentration of $\mathrm{TclA}$ is $\sim 10 \mu \mathrm{g} / \mathrm{ml}$.

\section{Recombinant transposase expression and purification}

E. coli strain BL21 pLysS was transformed with pRP470 containing the Tc1 transposase gene under the control of a T7 promoter (Vos et al. 1993), grown in $2 \times$ YT medium, and induced at an $\mathrm{OD}_{600}$ of $0.6 \mathrm{~nm}$ with $0.5 \mathrm{~mm}$ IPTG for $3 \mathrm{hr}$ at $37^{\circ} \mathrm{C}$. Inclusion bodies were purified as described by Nagai and Thogersen (1987). Inclusion bodies were dissolved in $8 \mathrm{M}$ urea, $20 \mathrm{~mm}$ sodium phosphate ( $\mathrm{pH} 6.0)$ and loaded on a CM cellulose CL-6B column (Pharmacia). The protein was eluted with a linear gradient from 0 to $500 \mathrm{~mm} \mathrm{NaCl}$. The transposase containing fraction was loaded on a Sephacryl S400 HR gel filtration column equilibrated in $6 \mathrm{M}$ guanidium hydrochloride, $50 \mathrm{~mm}$ Tris $(\mathrm{pH} 8.0)$. Transposase fractions were dialyzed against $8 \mathrm{M}$ urea, $50 \mathrm{~mm}$ Tris $(\mathrm{pH} 8.0), 1 \mathrm{mM}$ DTT. The protein was loaded on a S Sepharose FF column and eluted with $500 \mathrm{~mm} \mathrm{NaCl}$ in the same buffer. All steps were performed at room temperature. The protein was renatured by a $100 \times$ dilution into ice-cold buffer: $50 \mathrm{~mm}$ Tris (pH 8.0), $100 \mathrm{~mm} \mathrm{NaCl}, 5 \mathrm{~mm}$ DTT, $5 \mathrm{~mm}$ $\mathrm{MgCl}_{2}$. After $30 \mathrm{~min}$, insoluble protein was removed by centrif- ugation for $15 \mathrm{~min}$ in an Eppendorf centrifuge. Transposase concentration was $200 \mu \mathrm{g} / \mathrm{ml}$ and estimated to be $>90 \%$ pure

\section{In vitro transposition reactions}

Standard reaction conditions: $25 \mathrm{~mm}$ Tris ( $\mathrm{pH} 8.0$ ), $25 \mathrm{mM} \mathrm{NaCl}$, $1 \mathrm{mM}$ DTT, $10 \%$ ethylene glycol, $5 \mathrm{~mm} \mathrm{MgCl}_{2}$ for $2.5 \mathrm{~mm}$ EDTA), $4 \mathrm{~mm}$ spermidine, $0.05 \mu \mathrm{g} / \mu \mathrm{l}$ of BSA. Two hundred nanograms of donor plasmid was preincubated with $2.5 \mu \mathrm{l}$ of worm extract or $0.25 \mu \mathrm{l}$ of purified protein for $5 \mathrm{~min}$ on ice before addition of $2.5 \mu \mathrm{g}$ of target DNA in a total volume of 50 $\mu \mathrm{l}$. Incubation was for $1 \mathrm{hr}$ at $30^{\circ} \mathrm{C}$. Reactions were stopped by addition of $5.5 \mu \mathrm{l}$ of $250 \mathrm{~mm}$ Tris (pH 8.0), $50 \mathrm{~mm}$ EDTA, 5\% SDS, $2 \mathrm{mg} / \mathrm{ml}$ of proteinase $\mathrm{K}$. After $1 \mathrm{hr}$ at $37^{\circ} \mathrm{C}$, the DNA was precipitated and resuspended in $50 \mu \mathrm{l}$ of water.

\section{Mapping of in vitro cleavage sites}

Linear PCR amplification was in $20 \mu \mathrm{l}$ using $5 \mu \mathrm{l}$ of template and 0.5 pmole of primer for 20 cycles: $1 \mathrm{~min}$ at $94^{\circ} \mathrm{C}, 1 \mathrm{~min}$ at $60^{\circ} \mathrm{C}, 1 \mathrm{~min}$ at $72^{\circ} \mathrm{C}$, essentially as described (Craxton 1991). Sequence primers: BIGR $=5 \mp$ AGATTTCCACTTATATCATGTTTTATGTTTTGC, R2 (Van Luenen and Plasterk 1994).

\section{Genetic assay}

Electrocompetent DS941 lambda lysogen (Flinn et al. 1989) bacteria were prepared and used as described (Zabarovsky and Winberg 1990). The donor plasmid contains a lambda origin of replication and can not replicate in the DS941 lambda lysogen; the target plasmid has a Col El origin of replication. One to $5 \mu \mathrm{l}$ of DNA was used per electroporation, and $5 \%$ of the bacteria were, after dilution, plated on ampicillin. The remaining bacteria were plated on double selection. This yielded, depending on the efficiency, up to 200 transformants.

\section{Acknowledgments}

We thank our colleagues, especially Henri van Luenen and René Rezsohazy, for assistance, discussions, and comments on the manuscript, Annegien Broeks for microinjections, and Sean Colloms for the introduction of the $\lambda$ origin selection system. I.D.B. is supported by a European Community Human Capital and Mobility fellowship.

The publication costs of this article were defrayed in part by payment of page charges. This article must therefore be hereby marked "advertisement" in accordance with 18 USC section 1734 solely to indicate this fact.

\section{References}

Bainton, R.J., P. Gamas, and N.L. Craig. 1991. Tn7 transposition in vitro proceeds through an excised transposon intermediate generated by staggered breaks in DNA. Cell 65: 805-816.

Bainton, R.J., K.M. Kubo, J.-N. Feng, and N.L. Craig. 1993. Tn7 transposition: Target DNA recognition is mediated by multiple $\mathrm{Tn} 7$-encoded proteins in a purified in vitro system. Cell 72: 931-943.

Beall, E.L., A. Admon, and D.C. Rio. 1994. A Drosophila protein homologous to the human $\mathrm{p} 70 \mathrm{Ku}$ autoimmune antigen interacts with the $\mathrm{P}$ transposable element inverted repeats. Proc. Natl. Acad. Sci. 91: 12681-12685.

Bender, J. and N. Kleckner. 1986. Genetic evidence that Tn10 transposes by a nonreplicative mechanism. Cell 45: 801815.

Bolland, S. and N. Kleckner. 1995. The two single-strand cleavages at each end of Tn10 occur in a specific order during transposition. Proc. Natl. Acad. Sci. 92: 7814-7818. 
Boyd, A.C. and D.J. Sherratt. 1995. The pCLIP plasmids: Versatile cloning vectors based on the bacteriophage lambda origin of replication. Gene 153: 57-62.

Clark, J.M. 1988. Novel non-templated nucleotide addition catalyzed by procaryotic and eukaryotic DNA polymerases. $\mathrm{Nu}$ cleic Acids Res. 16: 9677-9686.

Collins, J., B. Saari, and P. Anderson. 1987. Activation of a transposable element in the germ line but not the soma of Caenorhabditis elegans. Nature 328: 726-728.

Craxton, M. 1991. Linear amplification sequencing, a powerful method for sequencing DNA. METHODS: A companion to Methods Enzymol. 3: 20-26.

Doak, T.G., F.P. Doerder, C.L. Jahn, and G. Herrick. 1994. A proposed superfamily of transposase-related genes: New members in transposon-like elements of ciliated protozoa and a common "D35E" motif. Proc. Natl. Acad. Sci. 91: 942-946.

Emmons, S.W., L. Yesner, K.-S. Ruan, and D. Katzenberg. 1983. Evidence for a transposon in Caenorhabditis elegans. Cell 32: 55-65.

Flinn, H.L., M. Burke, C.J. Stirling, and D.J. Sherratt. 1989. Use of gene replacement to construct Escherichia coli strains carrying mutations in 2 genes required for stability of multicopy plasmids. J. Bacteriol. 171: 2241-2243.

Grindley, N.D.F. and D.J. Sherratt. 1978. Sequence analysis of IS1 insertion sites: Models for transposition. Cold Spring Harbor Symp. Quant. Biol. 45: 125-133.

Grosschedl, R., K. Giese, and J. Pagel. 1994. HMG domain proteins: Architectural elements in the assembly of nucleoprotein structures. Trends Genet. 10: 94-100.

Henikoff, S. 1992. Detection of Caenorhabditis transposon homologs in diverse organism. New Biol. 4: 382-388.

Kaufman, P.D. and D.C. Rio. 1992. P element transposition in vitro proceeds by a cut-and-paste mechanism and uses GTP as cofactor. Cell 69: 27-39.

Kramer, J.M., R.P. French, E. Park, and J.J. Johnson. 1990. The Caenorhabditis elegans rol-6 gene, which interacts with the sqt-1 collagen gene to determine organismal morphology, encodes a collagen. Mol. Cell. Biol. 10: 2081-2089.

Mello, C.C., J.M. Kramer, D. Stinchcomb, and V. Ambros. 1991. Efficient gene transfer in C. elegans: Extrachromosomal maintenance and integration of transforming sequences. EMBO I. 10: 3959-3970.

Mizuuchi, K. 1992. Transpositional recombination: Mechanistic insights from studies of $\mathrm{Mu}$ and other elements. Annu. Rev. Biochem. 61: 1011-1051.

Mori, I. 1988. "Analysis of germline transposition and excision of $\mathrm{Tcl}$ transposable elements in Caenorhabditis elegans." Ph.D. thesis, Washington University, St. Louis, MO.

Müller, H.-P. and H.E. Varmus. 1994. DNA bending creates favored sites for retroviral integration: An explanation for preferred insertion sites in nucleosomes. EMBO $/$. 13: 47044714.

Nagai, K. and H.C. Thogersen. 1987. Synthesis and sequencespecific proteolysis of hybrid proteins produced in Escherichia coli. Methods Enzymol. 153: 461-481.

Paull, T.T., M.J. Haykinson, and R.C. Johnson. 1993. The nonspecific DNA-binding and -bending proteins HMGl and HMG2 promote the assembly of complex nucleoprotein structures. Genes \& Dev. 7: 1521-1534.

Plasterk, R.H.A. 1991. The origin of footprints of the Tcl transposon of Caenorhabditis elegans. EMBO J. 10: 1919-1925.

. 1995. The Tc1/mariner transposon family. In Transposable elements (ed. H. Saedler and A. Gierl). Springer Verlag, Heidelberg, Germany.

Pryciak, P.M. and H.E. Varmus. 1992. Nucleosomes, DNA- binding proteins, and DNA sequence modulate retroviral integration target site selection. Cell 69: 769-780.

Radice, A.D., B. Bugai, D.H.A. Fitch, and S.W. Emmons. 1994. Widespread occurrence of the Tcl transposon family: Tcllike transposons from teleost fish. Mol. \& Gen. Genet. 244: 606-612.

Rio, D.C., G. Barnes, F.A. Laski, J. Rine, and G.M. Rubin. 1988. Evidence for Drosophila $P$ element transposase activity in mammalian cells and yeast. J. Mol. Biol. 200: 411-415.

Robertson, H.M. 1993. The mariner transposable element is widespread in insects. Nature 362: 241-245.

- 1995. The Tc1-mariner superfamily of transposons in animals. I. Insect. Physiol. 41: 99-105.

Robertson, H.M. and D.J. Lampe. 1995. Recent horizontal transfer of a mariner transposable element among and between Diptera and Neuroptera. Mol. Biol. Evol. 12: 850-862.

Rosenzweig, B., L.W. Liao, and D. Hirsch. 1983. Sequence of the C. elegans transposable element Tc1. Nucleic Acids Res. 12: 4201-4209.

Shapiro, J.A. 1979. Molecular model for the transposition and replication of bacteriophage $\mathrm{Mu}$ and other transposable elements. Proc. Natl. Acad. Sci. 76: 1933-1937.

Van Luenen, H.G.A.M. and R.H.A. Plasterk. 1994. Target site choice of the related transposable elements Tc1 and Tc3 of Cacnorhabditis elegans. Nucleic Acids Res. 22: 262-269.

Van Luenen, H.G.A.M., S.D. Colloms, and R.H.A. Plasterk. 1994. The mechanism of transposition of Tc3 in C. elegans. Cell 79: 293-301.

Vos, J.C. and R.H.A. Plasterk. 1994. Tc1 transposase of Caenorhabditis elegans is an endonuclease with a bipartite DNA binding domain. EMBO /. 13: 6125-6132.

Vos, J.C., H.G.A.M. van Luenen, and R.H.A. Plasterk. 1993. Characterization of the Caenorhabditis elegans Tc1 transposase in vivo and in vitro. Genes \& Dev. 7: 1244-1253.

Way, J.C., L. Wang, J.-Q. Run, and A. Wang. 1991. The mec-3 gene contains cis-acting elements mediating positive and negative regulation in cells produced by asymmetric cell division in Caenorhabditis elegans. Genes \& Dev. 5: 21992211.

Zabarovsky, E.R. and G. Winberg. 1990. High efficiency electroporation of ligated DNA into bacteria. Nucleic Acids Res. 18: 5912 . 


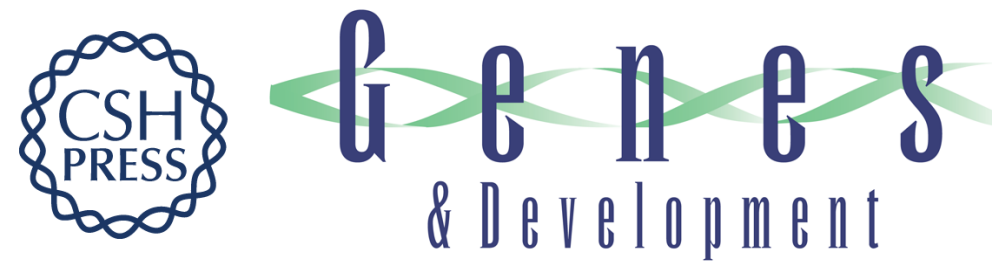

\section{Transposase is the only nematode protein required for in vitro transposition of Tc1.}

J C Vos, I De Baere and R H Plasterk

Genes Dev. 1996, 10:

Access the most recent version at doi:10.1101/gad.10.6.755

References This article cites 37 articles, 9 of which can be accessed free at:

http://genesdev.cshlp.org/content/10/6/755.full.html\#ref-list-1

License

Email Alerting

Service

Receive free email alerts when new articles cite this article - sign up in the box at the top right corner of the article or click here.

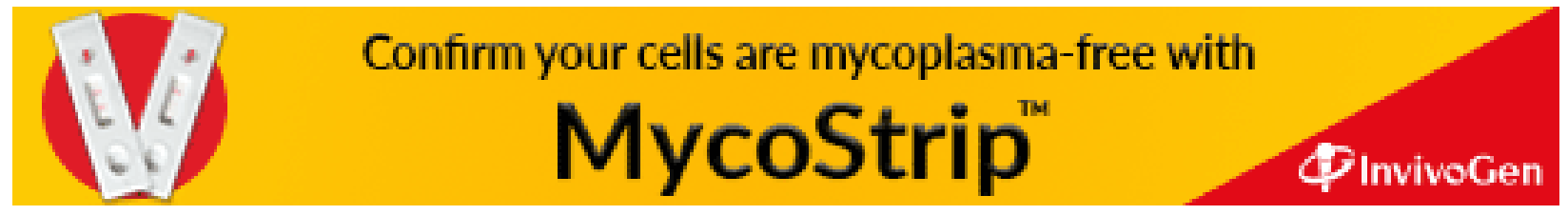

